\title{
OBSERVATIONS AS ASSETS IN DECISION SUPPORT
}

\author{
CJ Beegle-Krause ${ }^{(1)}$, Arthur Allen ${ }^{(2)}$, Frank L. Bub ${ }^{(3)}$, Eoin Howlett ${ }^{(1)}$, Scott Glenn $^{(4)}$, Josh Kohut $^{(4)}$, \\ Oscar Schofield $^{(4)}$, Eric Terrill ${ }^{(5)}$, Julie Thomas ${ }^{(6)}$, Michelle C. Tomlinson ${ }^{(7)}$ and Joaquín Tintoré $^{(8)}$ \\ ${ }^{(1)}$ Applied Science Associates, 55 Village Square Drive, South Kingston, RI 02881, USA, \\ Email: cjbk@Research4D.org; ehowlett@asascience.com

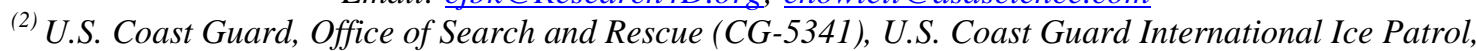 \\ 1 Chelsea Street, New London, CT 06320,USA, Email: Arthur.A.Allen@uscg.mil \\ ${ }^{(3)}$ Naval Oceanographic Office, 1002 Balch Blvd, Stennis Space Center, MS 39525, USA, \\ Email: Frank.Bub@navy.mil \\ (4) Marine and Coastal Sciences, School of Environmental and Biological Sciences, Rutgers, The State University \\ of New Jersey, 71 Dudley Road, New Brunswick, New Jersey 08901, USA, \\ Email: glenn@marine.rutgers.edu; kohut@marine.rutgers.edu; schofield@marine.rutgers.edu \\ ${ }^{(5)}$ Marine Physical Laboratory, Scripps Institution of Oceanography, 291 Rosecrans Street, San Diego, \\ La Jolla, CA 92106, USA, Email: eterrill@uscd.edu \\ ${ }^{(6)}$ Scripps Institution of Oceanography, 9500 Gilman Drive M/C 0214, La Jolla, CA 92093-0214, USA, \\ Email:jothomas@uscd.edu \\ (7) Coastal and Oceanographic Assessment, Status \& Trends Branch, NOAA (National Oceanic and \\ Atmospheric Administration) / Center for Coastal Monitoring \& Assessment, 1305 East-West Highway, \\ SSMC-IV, Silver Spring, MD 20910, USA, Email: John.Christensen@noaa.gov \\ (8) OceanBit and IMEDEA (Instituto Mediterraneo de Estudios Avanzados) (CSIC-UIB (Consejo Superior de \\ Investigaciones Cientificas /University of the Balearic Islands)), Parc Bit, Naorte, Bloc A, $2^{a}$ p. pta. 3, E-07121 \\ Palma, Spain, Email: jtintore@uib.es
}

\begin{abstract}
Natural disaster mitigation, maritime accident response (e.g. oil spills such as the Prestige in Spain), maritime Search and Rescue (SAR) operations, and protecting the public during Harmful Algal Bloom (HAB) outbreaks all share the common need: decision makers responsible for managing the incident require available reliable information, particularly observations of ocean and coastal conditions. Examples for SAR, oil spill response, port operations and $\mathrm{HAB}$ forecasting are explored to identify key aspects of observational systems. Design of an observational network should consider these end-user needs:
\end{abstract}

- Metadata Standards

- Assimilation-friendly data delivery

- Model validation usage

- Interoperability with Geographic Information Systems (GIS)

- User authentication

- User notification regarding system status

- Sufficient bandwidth for connectivity with users
- Archive capability

- Other user needs.

\section{INTRODUCTION}

Natural disaster mitigation, maritime accident response (e.g. oil spills such as the Prestige in Spain) and maritime Search and Rescue (SAR) operations, all share the common need that decision makers responsible for managing the incident require reliable information. Even for smaller scale events, such as Harmful Algal Bloom (HAB) outbreaks or beach closures due to other water quality concerns, the key to successful public protection is timely and accurate information. Decisionmakers require integrated and, often, multi-disciplinary information that provides sufficient understanding of the problem to evaluate mitigation strategies and their trade-offs. Environmental observational data inform emergency managers about the most recent field conditions, and constrain the possible outcomes.

This paper examines a common framework of Decision Support through evaluation of several use cases in order to define key elements of a system that can efficiently use observations from disparate platforms and sources. The goal of the U.S. Integrated Ocean Observing 
System (IOOS $®$ ) is to provide continuous ocean data to support Decision Makers across the public and private sectors. This paper describes how different national and regional IOOS $®$ initiatives play a significant role in this goal.

\section{THE DECISION MAKERS' PROCESS}

Decisions made during both emergencies and routine events such as water quality monitoring, involve tradeoffs, typically based on established criteria applied to best information available (e.g., observational data, model forecasts, sampling strategies). The decision process and selected information products should be targeted to define the decision point - "Go" vs. "No Go" or comparing one tradeoff to another, NRC (National Research Council) [4]. Availability of observational data is a key component in decision support, providing "truth" to the extent observations may be available. Observations provide information regarding the situation before and as close to the time of the event as possible. Unfortunately, observations are not the end of the story, as predictive capabilities are also required to aid decision makers to select among response options within a scenario. Decision makers generally follow the following process during an event:

1. Gather situational information (e.g. anecdotal information, observations) about the unfolding event.

2. Gather the necessary maritime meteorological and oceanographic environmental conditions in the area of interest and surrounding areas, and over the forecasted time of the event.

3. Make predictions of the unfolding event's potential impacts, and how response options could alter those potential impacts.

4. Make decisions to deploy resources and / or change public behavior.

5. Assess impacts of deployed resources and decisions on the evolution of the event or situation.

6. Continue to assess the situation (including observations) over the course of the event (repeat steps 1-5) and evaluate any recovery, at times modifying the course of action, until the event is concluded.

\section{THE OBSERVATION - MODEL CONNECTION}

Observations and heuristic or numerical forecasts are inextricably linked in the decision process. Real information via observations from the field allows experienced personnel to formulate a mental model of the situation. From the field information, the expert can select the appropriate forecast(s) to constrain the decision space regarding potential outcomes.
Why "waste time" on models? Why not just take lots of observations? For any real-time operations such as SAR or oil spill mitigation, observations represent a moment in time and are generally in a limited spatial envelope. Models apply physical processes to the environment to project the situation forward (or backward) in time, and extrapolate observations to a wider spatial domain. For example, in a region where tides are dominant, a current observation at slack tide would be totally wrong 6 hours later during the flood (or ebb). Getting a complete picture of the ocean using observations alone is difficult. No matter how much data collected, the chance of missing a vital piece of information is great.

A sophisticated numerical model integrates the observed information into a full 3-dimensional analysis and forecast (or hindcast) which can be explored as continuous fields, and provide insight into current and future conditions. That is, we can answer questions like: Where did this object come from or where is it going? As the surface cools, when will hypothermia set in? How long before the oil spill evaporates or mixes away? When will waves decrease so we can affect a rescue?

As the ocean moves and properties mix or change, a model extends observed data far beyond the boundaries of its original location in both space and time. In addition, while we may only be able to collect temperature data, a model can use this information to compute currents.

Why not create and rely on a climatology based on lots of observations? There are not enough observations to create a detailed climatology. To say the ocean is "sparsely observed" is a major understatement. Oceanographers will always be jealous of their counterparts in meteorology, as land-based observations are much more closely spaced than any observational system in the ocean. For example, in the ocean the Argo (Global array of free-drifting profiling floats) program now has 3000 profilers collecting temperature and salinity data in the upper $1000 \mathrm{~m}$ every 10 days. That is 300 observations/day, randomly spread over $70 \%$ of the globe and about $1 / 5$ of the ocean's depth. At this point, there are not enough observations to make an accurate, continuous climatology of the ocean.

Even if ocean sampling were increased to be comparable to the observations available in atmospheric sciences, a climatology is an average, and an average never represents any particular point in time. The ocean is moving and changing on scales that range from hourly to decadal (ocean data is becoming the one of the definitive indicators of climate change), and a model can show how this is happening.

How do observations contribute to models? First, they are used for verification. Comparisons between observations and concurrent model data give us 
guidance on model skill. Observations also allow us to assign uncertainty to the model products, which is extremely valuable to users of model data to evaluate its quality. The analysis of uncertainty in models is recognized as a priority in the modern development of models. In addition to using observations to validate models, observations are now regularly used for data assimilation in forecast models. Assimilation techniques allow models to incorporate the latest observations to improve their forecasts and provide a closer version of "reality".

\section{EXAMPLE SYSTEMS: SEARCH AND RESCUE OPERATIONS: U.S. COAST GUARD, USA}

\subsection{Need:}

SAR operations require data and information throughout the course of a SAR case. From 2006 to 2008, the United States Coast Guard handled 26,441 cases per year, conducted 26,955 sorties per year, and saved 5,118 lives per year.

SAR cases are often complicated by the lack of accurate information about the missing vessel or person at sea. In some cases, the Coast Guard may have an EPIRB (emergency position-indicating radio beacon) alert with information on the distress location, but many cases have very vague initial information such as "my husband left port to go sailing five days ago and we have heard nothing from the boat", or "the yacht left Newport for Bermuda two weeks ago, but never arrived".

An accurate picture of the recent ocean and meteorological conditions can give indications of where and when the survivors might have gotten into distress. Information on tracks of extreme weather, referred to as Hazards, may highlight likely areas of distress. Once the Coast Guard makes estimates on where the distress locations or Last Known Positions (LKP) are, surface wind and sea surface current fields are required to make trajectory estimates of the drift of missing objects. The drift models use the best available current and wind observations and forecasts to predict search areas for deployment of search vessels and aircraft. These assets will search using uniform flight or vessel paths referred to as search patterns. These search patterns are often parallel leg tracklines, with trackline spacing determined by the type of missing object. A person in the water is very hard to see, so very narrow track spacing may be needed to successfully see a floating person in the ocean. The track spacing is also determined by the quality of the visibility and weather conditions, which requires knowledge of the on-scene sea surface and meteorological conditions. In addition, small boat, cutter and aircraft operations all require environmental parameters to safely and effectively plan and conduct their missions.

\subsection{Observing System Solution:}

Regional Coastal Ocean Observing Systems around the United States have been installing higher resolution data collection systems that ultimately feed or verify high resolution coastal and harbor level numerical models. The numerical models provide the 'best' estimate of the present conditions and forecast the fields forward in time. These numerical "now" and forecasted fields are then made available via various web portals in a variety of native formats. The US Coast Guard has developed the Search And Rescue Optimal Planning System (SAROPS, Fig. 1) and an Environmental Data Server (EDS) to allow search controllers to (1) input all of the SAR case information, (2) predict future search areas using the best available data from the EDS, and (3) plan and deploy searches. The EDS aggregates data from numerous web sites and data distribution centers. These data are disparate, coming from observing systems such as satellite, in-situ buoys, sea surface radar and a variety of models. The EDS solves this problem by unifying these data into netCDF (Network Common Data Form/Climate and Forecast) standard formats. The EDS manages the temporal and spatial aggregation of observation and model data so that operators can use the best available observations for modeling drift in the past, and models for predicting future drift.

When a SAROPS user requests (using web services) particular wind or sea current products defined by latitude and longitude boundaries and over a specified time line, the EDS provides wind and current files to the SAROPS user typically within 10 seconds. Access to data must be efficient to meet the operational constraints of search and rescue mission planning.

In 2008, the Mid-Atlantic Coastal Ocean Observing System (MARCOOS) installed a long-range High Frequency (HF) radar network between Cape Cod and Cape Hatteras coupled to a statistical Short-Term Predictive System to provide forecasts out for 24 hours. The EDS is continually acquiring these data sets. The EDS is also presently being expanded to handle other environmental parameters used in SAR: Sea Surface Temperature (SST), wave conditions, visibility, river flow, precipitation, air temperature, ice cover, relative humidity and air pressure. 


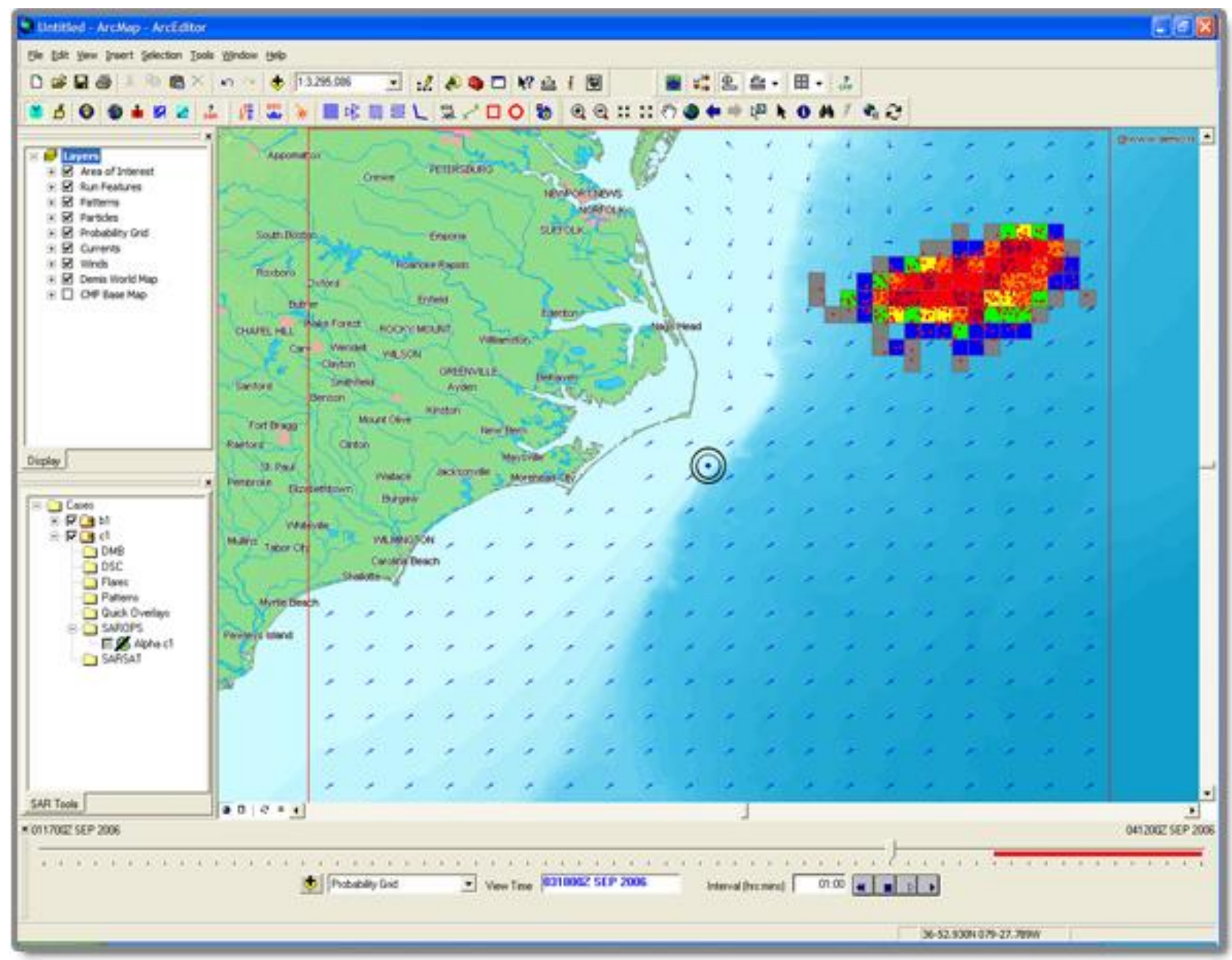

Figure 1. The U.S. Coast Guard Search and Rescue Optimal Planning System (SAROPS) demonstrating a sample case off Cape Hatteras, North Carolina, USA. Wind and current information, both observations and predictions, are shown in the operator window.

HF Radar in the Mid Atlantic Bight: Real-time surface current maps derived from HF Radar are an integral component of the IOOS®. A national committee on surface current mapping, supported by IOOS®, is currently refining an implementation plan for a National HF Radar Network for surface current mapping. The HF Radars will be operated by the 11 IOOS $®$ Regional Associations (RAs) and will provide data to a National Data Server for aggregation, product generation and distribution to users, both scientific and applied. Recently MACOORA, the Mid-Atlantic Coastal Ocean Observing Regional Association, identified HF radar as an important integrating component of their envisioned Regional Coastal Ocean Observing System (RCOOS).

MACOORA formed the Mid-Atlantic Regional Coastal Ocean Observing System (MARCOOS) to generate quality controlled and sustained ocean observation and forecast products that fulfill user needs. The first implementation phase of MARCOOS is an end-to-end regional ocean data acquisition, management, modeling and product-generation system developed in response to region-wide user needs in the thematic areas of Maritime Safety and Ecological Decision-Support. The same MARCOOS regional products further support the development of nested local products in thematic areas of Coastal Inundation and Water Quality. By coordinating, sustaining, and expanding ongoing ocean observing and forecasting activities, regional-scale data and products are now available in real time across the full Mid-Atlantic (MA) region and extending into the Bays and Sounds. The data is assimilated into 2D statistical and 3D dynamical ocean forecast models, driven by NOAA/NCEP ((National Oceanic and Atmospheric Administration/National Center for Environmental Prediction) standard atmospheric forecasts that include a dedicated NOAA-WRF (Weather Research and Forecasting) regional Sea breeze resolving forecast. Datasets and forecasts are delivered into operational decision-making systems, such as the 
U.S. Coast Guard SAROPS and EDS, through IOOS®compatible automated data servers for forecasting applications and a MARCOOS website. Outreach activities extend products to support ongoing NWS rip current forecasting projects and refine products for the fishing industry. The Mid-Atlantic HF Radar network now consists of one coastal network that covers the full range of the Mid-Atlantic coastal ecosystem from Cape Hatteras to Cape Cod with nested high-resolution coverage in Chesapeake Bay, Delaware Bay, New York Bight, and Long Island Sound. (Fig. 2).

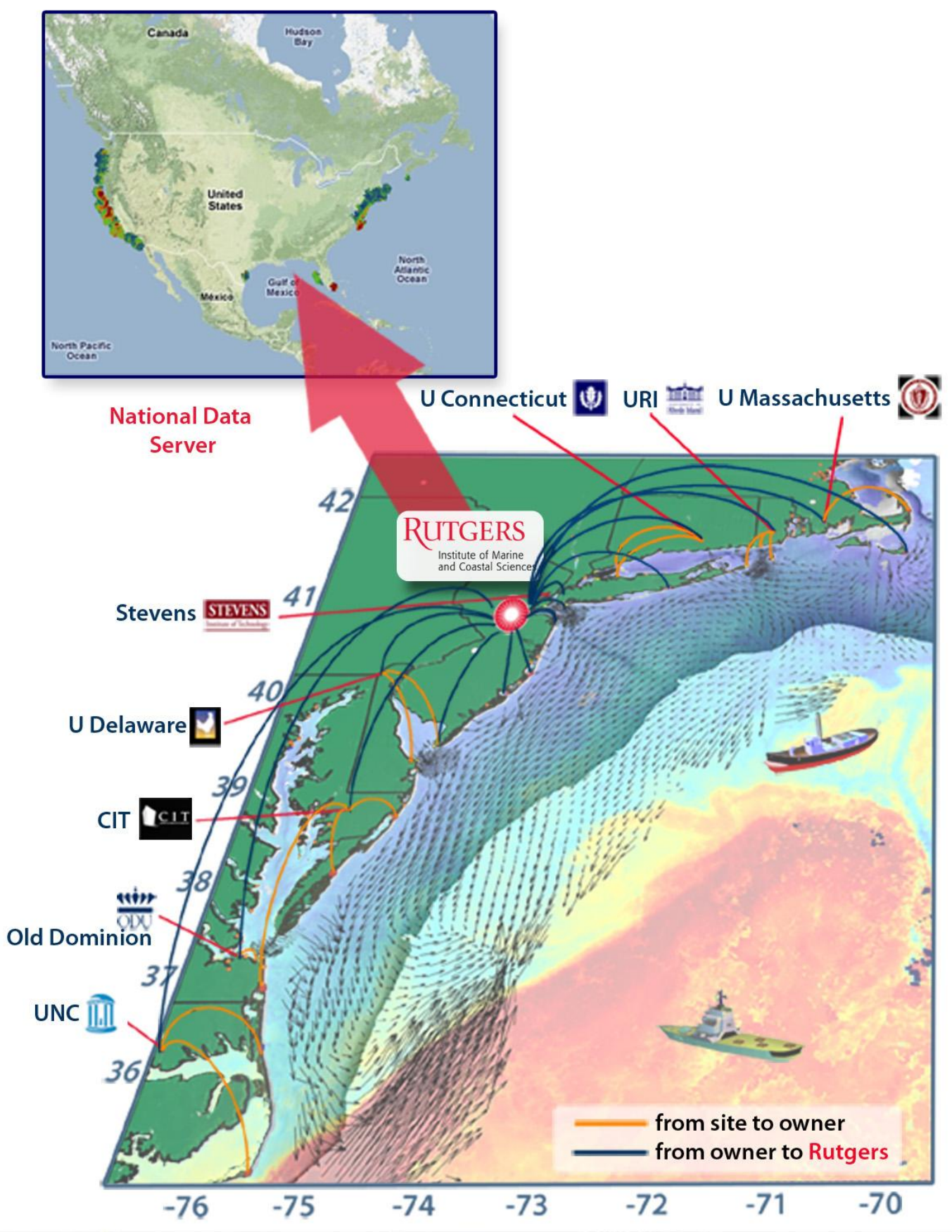

Figure 2. Map of MARCOOS HF Radar Network. The data flow is demonstrated as the movement of the observed radial data file from the radar site to node (orange line) and from node to central hub (blue). The radials are combined at the central hub and then displaved on the National Network. 
This regional network is recognized by the U.S. Coast Guard to improve their SAR activities and by NOAA Office of Response and Restoration ("NOAA / HazMat (Hazardous Materials)") to improve emergency response to hazardous spills. To reduce the lives lost, a critical U.S Coast Guard need is to optimize SAR operations to minimize search time. The major MARCOOS products for Maritime Safety are the 2D surface current fields observed by the HF Radar network and predicted by the statistical and dynamical forecasts. These observations and forecasts will be available to the search planners in the field. By providing surface current observations near the SAR incidents, search areas can be optimized.

The existing observational infrastructure and resident expertise is now being used to develop sustainable products to improve Maritime Safety. U.S. Coast Guard SAR controllers are the operators that direct deployment of aircraft and vessels using operational decision support tools (e.g. SAROPS). During an actual event, or test, a cluster of a few hundred virtual objects is deployed in surface wind and current fields downloaded from EDS and allowed to drift over time. The cluster disperses based on the uncertainty estimates in the winds and currents. If SAROPS data has lower uncertainties, then there is lower dispersion in the cluster, leading to a smaller search area and greater likelihood for success. Recent statistical comparisons between surface drifter trajectories, observatory enhanced predictions and the traditional approaches, which use climatology or nearest NOAA coastal station data, indicate that the enhanced predictions lead to more accurate results. In another recent study, comparisons between Coast Guard drifter-inferred currents and CODAR (Coastal Ocean Dynamics Applications Radar) surface currents indicate a factor of two improvement in uncertainty, as compared to the existing models. Thus, the U.S. Coast Guard has concluded that by using CODAR currents (with their estimated uncertainty) in the existing EDS for SAROPS, an additional 50 lives per year could be saved at the national level. MARCOOS continues to work with federal agencies to incorporate observatory products into search planning tools and procedures.

Network Operation: For the first three-year increment of IOOS $®$ funding, MARCOOS has sectioned the MidAtlantic HF Radar Network into three (3) regions a northern, central and southern region. There is one fully funded operator responsible for the sites in their respective region. The operators are geographically separated. Several tools have been implemented to bridge this geographic divide. A monthly conference call has been set for operators to communicate and share pressing issues. A collaborative development web site was created for the sharing of documents and as an archive of communications during the project. An advanced HF radar course was conducted by CODAR Ocean Sensors from February 18-22, 2008. The agenda was user-driven developed in collaboration with the manufacturer of the HF radar. A database was created where critical information on each site was centrally accessible and stored for a unified regional system. Best practices documents on radar antenna patterns and quality assurance and quality control of radial data were created to be shared among the HF radar operators. Data quality is maintained through a region-wide quality assurance workgroup. Through regular conference calls, validation activities are coordinated to ensure that the latest knowledge in HF radar quality control is implemented on the regional scale. This working group ensures that real-time quality controlled data is delivered to regional and national user communities.

At present 26 radar sites are operating in the MARCOOS region. Radial current data from each site is first collected at the local central computer sites for each of the nine (9) operators. The radial data is then aggregated at Rutgers as part of the National HF Radar data server supplied by NOAA. Locally, the radial data is used to produce a regional scale product that covers coastal waters from Cape Cod to Cape Hatteras, and to produce local high-resolution products in each of the bays. These data are currently displayed on the Rutgers Coastal Ocean Observation Lab website (http://marine.rutgers.edu/cool) to provide users a quick look at the datasets. The total vector fields are then made available for assimilation by the University of Connecticut's Short Term Prediction System (STPS) and via OPeNDAP (Open-source Project for a Network Data Access Protocol) servers for assimilation into an ensemble of three dynamical forecast models run by Rutgers, Stevens Institute of Technology, and University of Massachusetts - Dartmouth. Statistical and dynamical forecasts also can be viewed on the originator's websites, but, more importantly, are then transferred to the EDS so that these data are available to support SAR operations.

\subsection{Results:}

The available of real-time data and high resolution, accurate nowcast and forecast fields directly into the US Coast Guard's operational search planning software has significantly decreased the burden of gathering and inputting environmental data fields by the SAR controller; increased operator awareness of the complexity of the ocean currents; improved trajectory forecasts of survivors and survivor craft; and allowed the SAR controller to compare and contrast several different starting scenarios and environmental fields to assess the full range of possibilities. This has resulted in 
more effective planning of Coast Guard's search assets, which is expected lead to more lives being saved.

\section{EXAMPLE SYSTEMS: OIL SPILL RESPONSE: TANKER VESSEL PRESTIGE, SPAIN}

\subsection{Need:}

The T/V Prestige spill highlights the challenges posed by choices such as "Place of Refuge" (options for relocating a damaged vessel that may cause a spill). A decision of whether or not to offer safe refuge, where the damaged vessel can anchor temporarily for repairs, involves consideration of broad environmental and socioeconomic issues. If the vessel is allowed into port, and then leaks oil, the environmental damage could be very serious, and the public could view the decision as inappropriate and reckless. Alternatively, the risk of towing a disabled vessel out to sea was demonstrated when the T/V Prestige foundered in open water and polluted more than $1,000 \mathrm{~km}$ of coastline over three months. As with many emergency situations, "Place of
Refuge" is not solely a science-based decision; economic and social issues also need to be considered. There is no "zero risk solution", and an "acceptable tradeoff" must be found, Beegle-Krause et al [2]

\subsection{Observing System Solution:}

During the initial phase of the Prestige oil spill, in November 2002, and throughout the response, no official procedures existed at a national level for oil spill mapping, trajectory forecasting and no coastal environmental resource surveys or maps of environmental sensitivity to oil (ESI, Environmental Sensitivity Index) information were available. The imperative of a major oil spill mobilized a major scientific action to establish a science based decisionmaking procedure for oil spill trajectory determination and estimation of impact on the coast. An operational Oceanography Working Group was formally established, coordinated by the Spanish Research Council, CSIC (Consejo Superior de Investigaciones Científicas), on December 12th, through a specific mandate to CSIC from the Vice presidency and Ministry

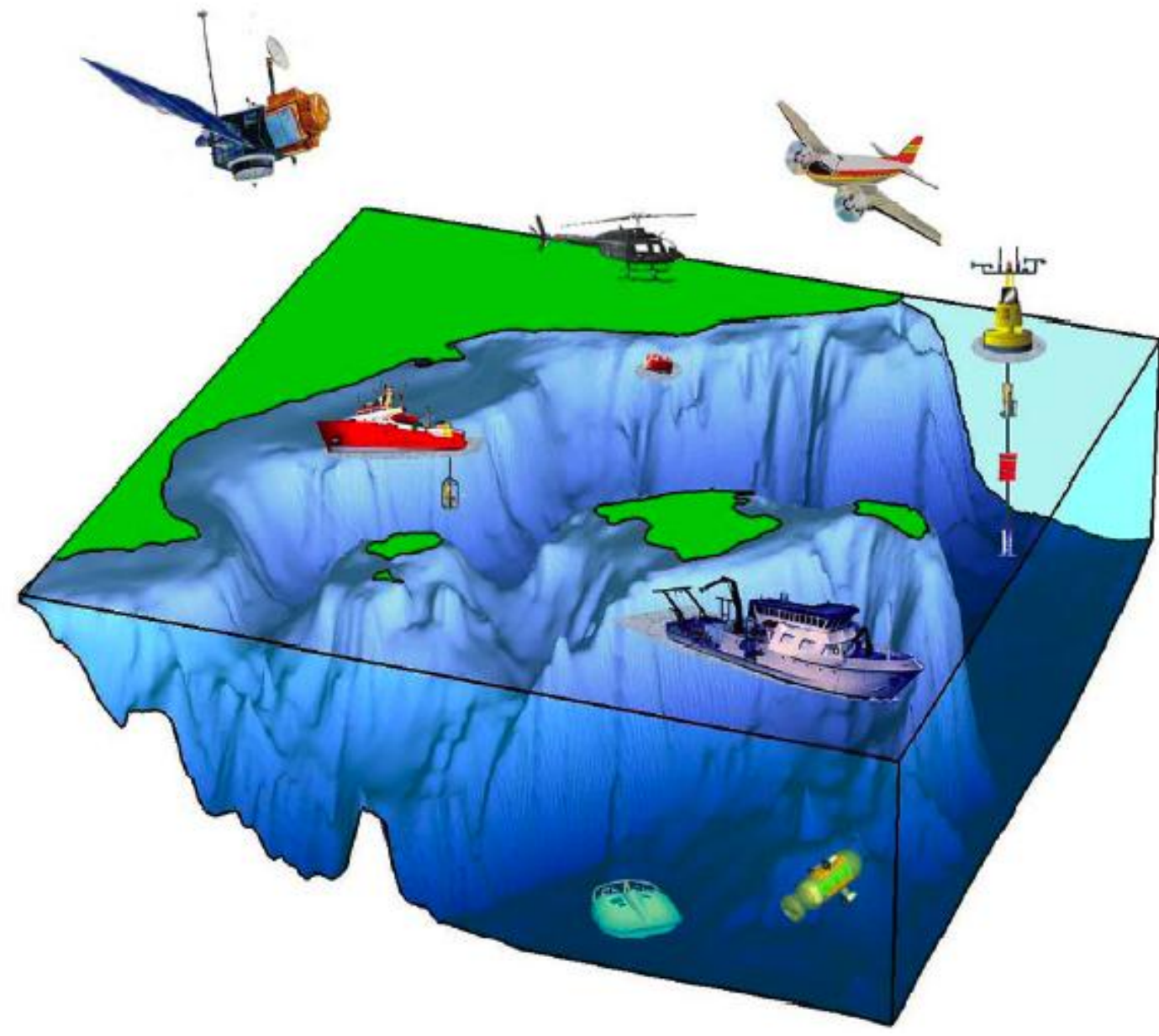

Figure 3. Schematic view of the observing system platforms used by the hybrid ocean forecasting system during the Prestige spill incident for near-realtime observations and prediction. 
of Science Secretary of State and included US National Oceanic and Atmospheric Administration (NOAA) scientists as key elements providing guidance to the scientific research community in Spain (including both observations and modelling).

The response involved numerous observational assets over the period of the response such as helicopters and fixed wing aircraft, and various meteorological stations. An unusual addition was an oceanographic research vessel with real-time observational capability that provided observations in near-realtime as input to a circulation model (Fig. 3). Integrating these information into an accurate operational picture was challenging as the spill crossed international borders, as response assistance from around the world were mobilized, and as the spill response began to dominate public media.

\subsection{Results:}

This was the first time the scientific community of Spain faced real operational oceanography in an extreme situation. Ultimately, the T/V Prestige spill precipitated the birth of operational oceanography in Spain, and new interactions between scientists and political decision makers, Jordi et al [3]. The successful results obtained were recognized at all levels (scientific, social, economical, etc), precipitating the beginning of today's ongoing work in Spain in Operational Oceanography which is discussed in Jordi et al [3], Alvarez-Fanjul [1] or more recently Onken et al [5].

\section{EXAMPLE SYSTEMS: PORT OPERATIONS / LONG BEACH, CALIFORNIA, USA}

\subsection{Need:}

All mariners who are inbound or outbound of the Ports of Long Beach / Los Angeles require high-resolution ocean conditions, which are critical to safe and efficient passage. The Ports of Los Angeles and Long Beach, when combined, are the 5th largest port in the world. The Los Angeles Pilots completed over 52,000 vessel movements in the last decade, and since year 2000, the Catalina Express has delivered over 6 million passengers to Catalina Island. The challenge to the Port is to assure that this vast amount of commercial traffic transits to and from the harbor safely. An integrated Internet site was needed to provide the maritime traffic with near real-time data for immediate transit decisions or for planning purposes through available forecast information.

\subsection{Observing System Solution:}

In 2007, the Southern California Coastal Ocean Observing System (SCCOOS) was funded to develop and disseminate in near real-time a customized website for the Ports of Los Angeles and Long Beach. This website leverages and integrates data from two existing program. The Coastal Data Information Program (CDIP), collaboratively funded by the United States Army Corps of Engineers and the California Department of Boating and Waterways, provides wave data, nowcast and forecast models. SCCOOS, funded by the California Coastal Conservancy, provides the surface currents. Additional parameters are being added to the site such as winds and tides. The website was developed with stakeholder input from the maritime community

(http://sccoos.org//data/harbors/lalb/fullscreen.php).

\subsection{Results:}

The maritime community responded to the website by providing latitude/longitude locations that are critical to their operations (green dots in Fig. 4). A user can mouse over these locations receiving wave spectra, surface currents and winds. One example of a specific product is the automated messages sent to Jacobsen Pilots in Long Beach when certain forecast conditions are exceeded. Long period waves (greater than 12-14 seconds) will cause the super tankers to start pitching. The tankers are approximately 1000 feet long and have a draft of 80 feet. As the tankers start pitching, they run the risk of hitting the bottom at the Channel entrance. Notification of the projected long period swell allows better planning of vessel control. Discussions are underway as to how this site can serve as a template for additional ports and harbors, providing decision-makers with the necessary information for safe passage.

The San Pedro Channel at the entrance to the Port is often challenging for the mariner. The benign climatic conditions of Southern California can fool an inexperienced mariner. If the swell is from due west, wave conditions in the deep canyon at the entrance to the Port can be quite energetic. Also, in the lee of Catalina Island, the sea conditions can be calm. Once out of the shelter of the island, on the approach to the Port, conditions can become more severe. The Catalina Express ferry, transiting between the Port and Catalina Island, is another Ocean Observing user who benefits from the product. Checking the SCCOOS site with realtime waves, currents and winds is critical to maritime safety. 


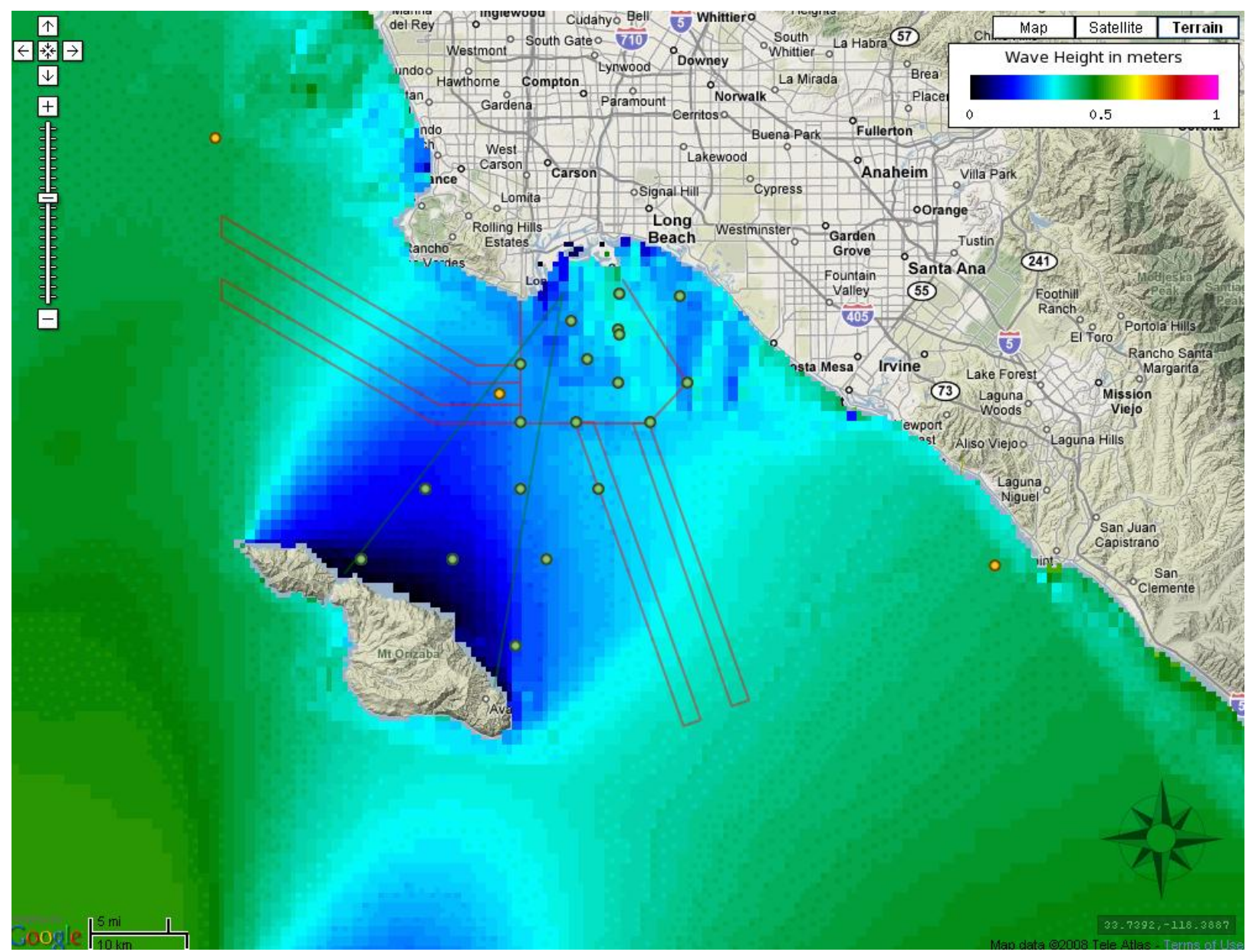

Figure 4. Port Operations example data for San Pedro Channel. Colors indicate wave conditions in the area. The island shadowing effect is noticeable from the blue colors on the leeward side of Catalina Island.

This project is a key example of IOOS ${ }^{\circ}$ goals. IOOS ${ }^{\circ}$ was designed and developed with the intent of turning data into useful products that can provide the public with decision-making tools. This project demonstrates a coordinated network of people and technology that work together to generate and disseminate continuous data on our coastal waters. The Port of Los Angeles/Long Beach project is an example of a regional contribution to IOOS®.

Efforts are also underway to integrate these data with the NOAA Physical Oceanographic Real-Time System (PORTS). This collaboration will be beneficial as the PORTS display is widely utilized by the maritime community.

\section{EXAMPLE SYSTEMS: HARMFUL ALGAL BLOOMS (HABS)}

\subsection{Need:}

Blooms of the toxic dinoflagellate, Karenia brevis, occur nearly every year on the Gulf coast of Florida, typically between August and December, and are reportedly the most common $\mathrm{HAB}$ occurring in the eastern Gulf of Mexico, Stumpf [5]. Numerous fish kills and various marine bird and mammal deaths have been linked to $K$. brevis blooms, and very low levels $(5,000 \mu \mathrm{g} / \mathrm{L})$ of $K$. brevis prompt the closure of shellfish beds to prevent Neurotoxic Shellfish Poisoning (NSP) from human consumption of contaminated shellfish. Under certain wind conditions, nearshore surface blooms release a potent brevetoxin aerosol that is a serious health issue, producing respiratory illness and distress in beachgoers.

\subsection{Solution:}

In order to assist coastal communities, a new ecological forecast system was developed for the Gulf of Mexico through a multi-office effort of NOAA. In October 2004, this system was transitioned from research to operational status, creating the Gulf of Mexico HAB Operational Forecast System (GOM HAB-OFS). GOM HAB-OFS bulletins (Fig. 5) are produced twice weekly 


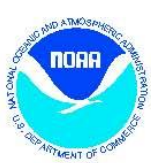

Gulf of Mexico Harmful Algal Bloom Bulletin Region: South Florid

6 October 2008

NOAA Ocean Service

NOAA Satellites and Information Service

NOAA National Weather Service

Last bulletin: October 2,2008

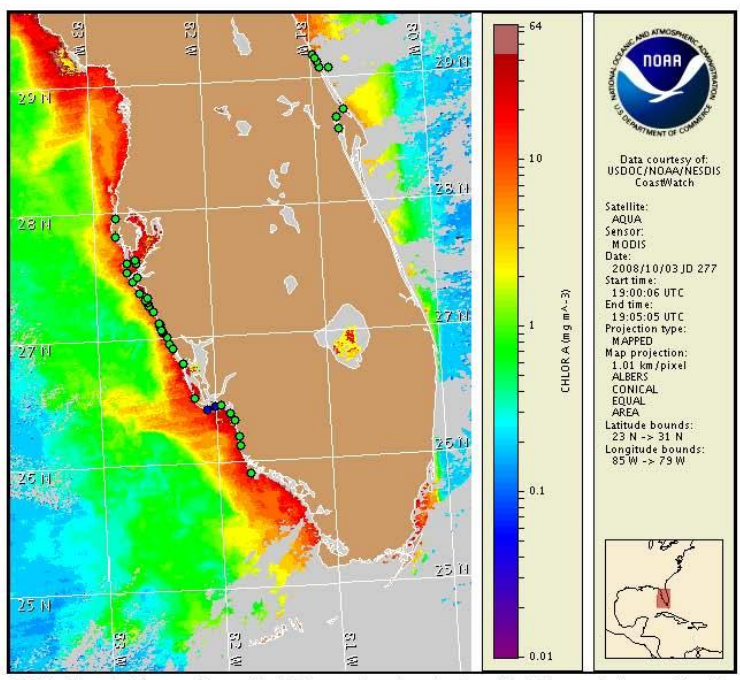

Satellite chlorophyll image with possible $\mathrm{HAB}$ areas showm by red polygon(s). Cell concentration sampling daa from September 26 to October 1 shown as red (high), orange (medium), yellow (low b), brown (low a), blue(very low b), puple (very low a), pink (present), and green (not present). For a list of cell count $d$ di http://tidesandeurrents.noaa_govhabhabfs_bulletin_zuide.pdf

Please note the following restrictions on all SeaWiFS imasery derived from CoastWatch. Data are restricted to civil marine applications only; i.e. federal state, and local govenment use/distribution is permitted.

Image produets may be published in newspapers. Any other publishing arrangements must receive GeoEye approval via the Coast Watch Program
Conditions Report

A harmful algal bloom has been identified in southern Lee County. Patchy very low impacts are possible in the eastern Sanibel Island region Monday night and Tuesday night through Thursday. No other impacts are expected alongshore southwest Florida today through Thursday, October 9

Analysis

A harmful algal bloom has been confirmed in southern Lee County, 'Very Low b' concentrations of Karenia brevis were identified onshore Sanibel Island, Lee County (Tarpon Beach and Lighthouse Beach) on 10/1 (FWRI). Background concentrations were also reported onshore near New Pass in Sarasota County on 9/29 (MML). No additional $K$ brevis was identified alongshore southwest Florida from Pinellas to Collier Counties, or offshore southwest Florida from Manatee to Lee Counties, in the past week (SCHD, FWRI, MML; 9/29-10/3).

Recent MODIS imagery indicates that chlorophyll levels significantly intensified offshore southern Lee and northern Collier Counties (up to 12 miles) between 10/1 and 10/3.

High chlorophyll levels $\left(>10 \mu \mathrm{m} / \mathrm{L}\right.$ ) are visible near Sanibel Island (from $26^{\circ} 25^{\circ} 25^{\prime \prime} \mathrm{N}$ $82^{\circ} 2^{\prime} 54^{\prime \prime} \mathrm{W}$ eastward to $26^{\circ} 25^{\prime} 14^{\prime \prime} \mathrm{N} 81^{\circ} 58^{\prime \prime} 39^{\prime \prime} \mathrm{W}$ and northeast to $26^{\circ} 26^{\circ} 49^{\prime \prime} \mathrm{N}$ $\left.81^{\circ} 57^{\prime} 21^{\prime \prime} \mathrm{W}\right)$; and additionally alongshore southern Lee to northern Collier County (south to $26^{\circ} 12^{\prime 1} 19^{\prime \prime} \mathrm{N} 81^{\circ} 50^{\prime} 52^{\prime \prime} \mathrm{W}$ ). A larger elevated to high (greater than $3 \mu \mathrm{g} / \mathrm{L}$ ) chlorophyll feature is visible up to 114 miles west and southwest of Sanibel Island. High chlorophyll levels $(>10 \mu \mathrm{g} / \mathrm{L})$ are also visible alongshore Gasparilla Island and Cayo Costa in northern Lee County. Sampling is highly recommended in each of these locations.

Conditions were favorable over the weekend for further intensification of the existing bloom in the Sanibel Island region and for bloom formation elsewhere along southwest Florida. Further intensification of the bloom is possible through Thursday. Slight southerly transport is possible today through Wednesday.

Bulletins will now be issued twice weekly on Monday and Thursday while harmful bloom conditions remain.

Please note that due to technical difficulties, SeaWiFS imagery is temporarily unavailable for display in this bulletin; MODIS imagery is shown on pages 1 and 3 of this bulletin.

Fisher, Fenstermacher, Gan

Figure 5. Sample Harmful Algal Bloom Bulletin.

during active bloom events (once weekly during inactive bloom status) and provide information concerning the possible presence or confirmed identification of new blooms, and monitor existing blooms through forecasts of spatial extent, transport, and intensification. The production of the nowcast/forecasts relies on a series of physical and biological data, along with a heuristic model. The primary tool used to indicate a bloom is an ocean color image product, which indicates an increase in chlorophyll over the preceding two months, Stumpf et al [6]. The imagery, along with $K$. brevis field samples provided by the state of Florida, and forecasted wind conditions form the Marine Weather Forecast inputs into the heuristic model. The model is then used to forecast $\mathrm{HAB}$ related conditions for up to a maximum of 4 days. The current spatial resolution of the forecasts is approximately $30 \mathrm{~km}$.

\subsection{Results:}

The forecasts provide a daily coastal impact statement pertaining to the human health impacts (respiratory irritation) that are publicly available at http://tidesandcurrents.noaa.gov/hab/. As a result of these forecasts, advance cautionary notice can be issued to protect beachgoers from respiratory illness; necessary mitigation actions, such as closing shellfish beds, can be initiated before a bloom becomes a coastal hazard; and mass marine animal casualties can be minimized through advanced response

\section{CONCLUSIONS: KEY OBSERVING SYSTEM ATTRIBUTES FOR DECISION SUPPORT}

Many considerations exist when designing and implementing an observational system. Below is a list 
of priority criteria applicable to general system design:

1. Metadata standards for inventory are key for allowing the maximum number of users to find and assimilate observations into their own systems.

2. Assimilation-friendly delivery of in-situ and remote sensed real-time observations (taking into consideration the limitations of the GTS) allows users to more easily make use of observational information

3. Improving model validation capabilities should be a key consideration in observing system design. Observing System Simulation Experiments (OSSEs) and Observing System Experiments (OSE) are methodologies for design and iteration to maximize public benefit from the system.

4. Interoperability with GIS systems and their users requires standards, tools, and best practices through the use of the OGC (Open Geospatial Consortium) WxS standards (WMS- Web Map Service, WFSWeb Feature Service, and WCS-Web Coverage Service). Information on geoid, horizontal datum and vertical datum used is very important to include in the metadata.

5. User authentication and authorization for data access to observational and model data using "pull" services like OPeNDAP.

6. Notification in real-time of both of data availability (new data) and unavailability (interruptions to data flow or changes in content or format) situations. This information is needed to support real time data assimilation and model initialization

7. Sufficient Bandwidth for timely delivery to the users.

8. Archive of observations allows users increased analysis capability through longer time series.

9. User needs: the above list is not exhaustive, as special situations require specific observations and information products. Communication with user groups ensures that systems are always providing information that benefits society.

\section{REFERENCES}

1. Alvarez-Fanjul, E; Losada, I; Tintore, J, et al.., 2007: The ESEOO project: Developments and perspectives for operational oceanography at Spain. 17th International Offshore and Polar Engineering Conference (ISOPE 2007). Lisbon, Portugal. Proceedings of the Seventeenth (2007) International Offshore and Polar Engineering Conference, Vol. 1- 4. Pages: 1708-1715.

2. Beegle-Krause, CJ, Wayne Munns, Amy Merten, Bill Lehr, Joaquín Tintoré, Joel Baker, Greg Chini, Nancy Kinner, Tracy Collier, Charles Vörösmarty (2007). "Emergency
Response in Coastal Waters: Scientific Support for Dynamic Decision Making" Unpublished manuscript.

3. Jordi, A., M.I. Ferrer, G. Vizoso, A. Orfila, G. Basterretxea, B. Casas, A. Álvarez, D. Roig, B. Garau, M. Martínez, V. Fernádez, A. Fornés, M. Ruiz, J.J. Fornós, P. Balaguer, C.M. Duarte, I. Rodríguez, E. Alvarez, R. Onken, P. Orfila, J. Tintoré, 2006. Scientific management of Mediterranean coastal zone: A hybrid ocean forecasting system for oil spill and search and rescue. Marine Pollution Bulletin 53:361-368.

4. National Research Council. 2003. Environmental Information of Naval Warfare. Committee on Environmental Information for Naval Use, Ocean Studies Board, Division of Earth and Life Sciences. The National Academies Press, Washington, DC. 203 pp.

5. Onken, R., A. Álvarez, V Fernández, G. Vizoso, G. Basterretxea, J. Tintoré, P. Haley, E. Nacini (2008). A forecast experiment in the Balearic Sea. Journal of Marine Systems Vol 71, pp 79-98.

6. Stumpf, R.P., M.E. Culver, P.A. Tester, M. Tomlinson, G.J. Kirkpatrick, B.A. Pederson, E. Truby, V. Ransibrahmanakul, M. Soracco. 2003. Monitoring Karenia brevis blooms in the Gulf of Mexico using satellite ocean color imagery and other data. Harmful Algae 2: 147-160. 